\title{
Shifting Directions in the Arts: Building Quality Online Courses and Degree Programs
}

\author{
A. Munson, Member, IACSIT, L. Archer, E. Eanes, D. Garziano, and D. Hutchinson
}

\begin{abstract}
The landscape of virtual learning is vast, filled with rich opportunity and need to grow new programs, reach innovative learning experiences, and offer extraordinary opportunities for students who otherwise might not have the opportunity for a quality education. Like any area of learning, the virtual one also has areas that lack the understanding or transformation in pedagogy needed for proper growth, as many associate with online learning in the arts. The focus of this paper is the path one University arts college pursued to nurture the field of content and technical challenges, pioneering a well-laid foundation for virtual learning experiences in all areas of the arts.
\end{abstract}

Index Terms-Arts degree programs, computer mediated communication, distance learning in the arts, technology in the arts.

\section{INTRODUCTION}

Distance learning in the United States is a thriving landscape, one that more and more universities and institutions are beginning to cultivate. Though its practice originally developed from the need to address issues of accessibility, both physical and geographical, practitioners have expanded its operation into other avenues, realizing the plethora of opportunities that virtual platforms offer. Nonetheless, the pedagogical and epistemological shifts required for such developments can be jarring, for systems of education are historically founded upon face-to-face teaching and learning. For this reason, Moore and Kearsley posit that education is in the midst of a "Copernican revolution" [1].

As the culture of education indeed undergoes a radical transformation, its manifestations will vary across disciplines. The study of the arts is one area in which the theories and practices of distance learning have not yet fully permeated. Organizing structures of arts departments across the United States are just beginning to acquaint themselves with the practices and possibilities of distance learning, which many other disciplines have enjoyed for decades. Despite this lag, the College of the Arts (COTA) at Kennesaw State University (KSU) is at the forefront of this endeavor: to harness the possibilities of distance learning in the arts.

Kennesaw State University (KSU) is a relatively young university, having just celebrated its 50th birthday in 2013. KSU currently supports nine colleges and serves a student body nearing 30,000 and representing 130 countries. Positioned in a suburb of a major metropolitan city-Atlanta,

Manuscript received June 30, 2014; revised September 12, 2014

The authors are with Kennesaw State University, U.S.A. (e-mail: amunson@kennesaw.edu, larcher@kennesaw.edu, eeanes@kennesaw.edu, dgarzian@kennesaw.edu, dhutchi8@kennesaw.edu).
Georgia - KSU's student body has historically consisted of a regional, commuting population. While youthful, the university has quickly gained national recognition and merit in many areas including: innovator of the year for the farm to campus food program; "best place to work" ranking in US News and World Report; Sen. Paul Simon Award for campus internationalization; and among the top universities in the country for veterans. In addition to significant strides in growth, quality, recognition, and prestige, the university has also committed to offering quality online programs to support an even greater student population, as well as serve the needs of existing students living off campus and commuting to class.

$\mathrm{KSU}$ is rapidly expanding the courses and degree programs offered online. Although the College of the Arts (COTA) has traditionally offered the lowest number of courses online within the university, the growth of COTA online offerings has tripled in the last three years. As KSU continues to support and promote online learning, the College of the Arts is thoughtfully examining systems and models that foster quality educational practices while being sensitive to student needs and the ever-expanding opportunity for online education.

Recognizing the growth and potential in offering the arts online, in 2014 the COTA dean appointed a working group to focus on quality teaching, learning, and innovation specific to online, hybrid, and low residency arts courses and degree programs. Each of the four areas of the college was represented in this group: dance, music, theater, and visual arts. During a six-week intensive study, this collaborative team surveyed literature and best practices in those four disciplines as well across the arts at large to note and better understand the state of teaching the arts online. After the collection of research and its careful analysis, the results of the study were determined and are now offered here. This paper examines: the shifting directions in the arts and the opportunities to motivate, encourage, and incentivize faculty; current courses that may easily be transitioned to a virtual platform; and opportunities for the College of the Arts to be a leader in online learning in the state of Georgia, USA.

\section{Supporting InNOVATION IN TEACHING AND TECHNOLOGY}

Barriers to offering arts courses and degree programs online are due, in part, to the perceived nature of the performing and visual arts, both in their preparation and presentation. Growth and active learning in an arts course often occurs through extensive and continued practice in the studio. Students are then typically required to present visual or performance pieces for evaluation. This dominant, tested 
model of teaching and learning in education can foster a resistance toward modification [2], [3], engendered by the ever-pervasive "if-it-isn't-broke-don't-fix-it" mentality. The experiential and, at times, ephemeral nature of the arts only reinforces such reservations.

However, without investigating the advantages of shifting arts courses and programs online, newer modes of thinking, teaching, and learning become less imaginable. Thus, as progress ushers in new opportunities for education, it becomes important for faculty to approach course design with both a consciousness of and openness toward new modes of delivery [4].

While indifference and hesitation can be powerful forces for preventing change in arts education, it is certainly not the only obstacle. Issues of accessibility, availability, and knowledge of content dissemination regarding newer technologies stymie faculty and their potential contributions to distance learning in the arts. This barrier, coupled with the possible uncertainty of faculty to incorporate virtual experiences, calls for specific, targeted, and institutionally supported opportunities for motivation and education. The College of the Arts at KSU has implemented a number of initiatives that aim to accomplish such goals, with the following guidelines in mind.

1) Instruction should be framed with an understanding that the use and purpose of technology within the arts requires a unique criteria set.

2) Faculty should have the opportunity to see firsthand the online innovation that is already occurring in the college. This may be done during a brief segment at the opening of the college, or at the first department meetings of the year.

3) Given their expressed interest and desire, faculty should have proper training so they feel prepared for the design of an online or blended course [1]; training and course design can take place during a "boot camp" format.

4) Financially supported attendance to workshops would help to further benefit faculty learning and engagement with distance learning; these workshops would focus on technologies that could advance both hybrid and online courses.

It is important to note that some courses and degrees, as they currently exist, may not be as suited to the virtual experience due to the requirements of equipment, space, and health regulations in order to experience materials and the technical processes involved. For instance, studio-based arts courses require unique resources that would be too difficult or costly for students to acquire - large rehearsal spaces and performance venues, costly tools and equipment, and the knowledge and physical oversight needed for safe and proper use of tools and equipment. As a result, attention to tactile, experiential, and face-to-face learning has been a cornerstone of arts education [5].

Nonetheless, even under overwhelming hesitation toward online arts courses, many technologies those are already available for the employment in distance learning can also be incorporated to improve face-to-face teaching and learning experiences. Knowledge and application of these technologies may also allow for a stronger consideration of what components of courses could be taught via a blended format. Embracing changes in communicative modalities can ultimately serve as a catalyst, not an obstacle, in the arts classroom [6].

Through COTA initiatives, faculty members have consistently engaged in innovative teaching methods. The provision of opportunities for growth in this area continues to enhance and advance the quality of teaching and learning at KSU.

\section{INCREASING ONLINE COURSE OFFERINGS}

The College of the Arts has made strides in supporting faculty in their online course development, design, and delivery needs. A survey of the college's current and upcoming offerings demonstrates such strides.

COTA has twenty courses approved for teaching online or currently under review: four courses in Art Education (Visual Art for Early \& Middle Grades; Technology and Computer Applications, Curriculum, Assessment, Classroom Management in Art Education, and Contemporary Issues in Visual Arts); two courses in Visual Arts (Arts in Society: Visual Arts and Introduction to Web Design); two courses in Art History (Renaissance Through Modern Art, History of Printmaking); two courses in Dance (Arts in Society: Dance and Dance History 2); four courses in Music (Arts in Society: Music, Introduction to Symphonic Literature, Introduction to Jazz, Fundamentals of Music); and seven courses in Theatre and Performance Studies (Broadway to Hollywood: Musical Theatre on Stage and Film, Play Analysis for Production, Performing Personal Narrative, Visual Imagination, Performing Classical Myth, and two Special Topics courses).

While it is important to recognize the established courses, it is also necessary to look forward and examine the possibilities of online course development in the arts, given the growing interest of institutions, faculty, and students in online offerings [7].

Such a survey rendered a list of additional courses at KSU as prime candidates for an online format. These include: Music History $1 \&$ 2, Dance History I, Theatre History 1-3, History of Popular Music, upper level pedagogy courses, senior seminars, Dance Analysis and Criticism, Introduction to American Music, Dramaturgy, Costume Design, and Art as a Public Profession among others.

It is likely that some of these courses will take form in the virtual environment in the coming years. Faculty members have responded exceptionally well thus far to designing courses during a two-week intensive created specifically for COTA. All faculty members who have experienced this intensive indicated they would "absolutely" recommend the experience to others interested in online course development. Thus, increased participation in online course development in COTA is expected.

\section{COTA: A PROMISING LEADER OF DISTANCE LEARNING IN THE ARTS}

A thorough review of existing research as well as quality programs led to the conclusion that promoting the arts online is a relatively quiet landscape. There are a number of programs reviewed based on extensive marketing and/or rankings by various agencies. While each has some piece of 
distance learning and the arts, there is not a comprehensive, holistic approach to teaching the arts online found in Georgia, or elsewhere.

Twenty-three programs offering the arts online were reviewed including Boston University, the Savannah College of Art and Design, and Kent State University. The review criteria included (but was not limited to): Courses/programs offered; technology required; overall impressions; ease of use/navigation; and possible applications for the College of the Arts. For-profit online arts institutions received the most attention and also skepticism. These institutions place great emphasis on advertising and recruitment, working to corner the industry in online arts education experiences. Even so, the majority of the programs focus on offering certificates, courses or degrees in the history of the arts, graphic design, or photography. Another trend is the growth of fully online Master's degrees in Music Education and Art Education, which target the public school teacher.

The University System of Georgia (USG) currently offers at least three arts degrees fully online, including two Master's Degrees in Music Education and one in Music Therapy. However, No USG institution has online degree programs offered in each of the arts disciplines. The support for distance learning, community engagement, and sensitivity to duplication in degree offerings provides prime opportunity for COTA the advance as a whole, moving toward offering degrees in each discipline that would serve as either online or low residency. The need for graduate programs, and interest and support of administration, faculty, staff, and potential students, serves as an incredible catalyst to move KSU forward by offering online/low-residency degrees in the following: MA in Art Education, MA in Music Education, MFA in Dance, and an interdisciplinary degree in Arts Administration.

When considering the survey and its subsequent analysis, it is worth noting that the make-up of the collected list consisted largely of history and theory courses in the arts. This trend was not only evident in the programs at KSU, but also in other arts programs across the country, as the research elucidated. Despite this overwhelming trend in online course offerings, consideration must be given to the possibilities of computer-mediated communication systems in web-based studio arts courses. While many studies support the validity of synchronous interchanges in an online course [8], [9], technologies such as video conferencing and their employment in practice-based online arts courses is appropriate and can help carve out a new direction for the arts [10], [11].

\section{CONCLUSION}

The current state of teaching the arts online in higher education is wide open. A few well-established colleges and universities have developed fully online graduate programs in arts education. But most others are still in the infancy stages and offer isolated courses that are primarily taught by a minority of their arts faculty.

This paper has examined the need and particular challenges with increasing virtual offerings in the arts including: faculty resistance; the experiential nature of arts instruction; and technology limitations for both faculty and students. While recognizing that some courses and degrees are not as easily transitioned to an online environment, the authors have recommended course areas that would be appropriate for conversion, such as arts pedagogy, history, and criticism courses. However, as greater understanding of capabilities and collaborations in virtual learning amasses, there develops the potential for a shift in the very definition of "studio practice." The authors maintain that openness towards such new and different practices is vital to the cultivation of virtual learning in the arts.

While there is a broad range of quality distance learning research, as we grow into the 21 st century understanding of teaching and learning, there is a need to address the gap between quality distance learning research and quality arts learning and teaching experiences. Integration of the data and analysis across disciplines engaging distance learning practices, as well as a greater understanding of technical applications, could contribute toward a robust presence in distance learning in the arts. As the arts move in the direction of exploring how distance learning could occur at all levels, the impact of the virtual learning experience for the student of the arts and the quality of teaching by faculty should be continually evaluated.

If online arts education is to thrive in the future, several components are critical. The understanding of change in pedagogy, the nature of learning, and the definition and function of teaching need examination with a consciousness of the relationship to the arts. Faculty will require access to intensive "boot camp" experiences to facilitate mastery of current technology, as well as to develop online and hybrid courses. These experiences must be specific to the arts in order to be useful. Moreover, given the heavy workload of many faculty members, their participation also must be financially supported by arts administrators. These factors are already in place in the College of the Arts at Kennesaw State University. Perhaps most important is the need for faculty to recognize the change in the 21 st century learner.

In midst of an era of metamodernism, innovation in conceptualizing all fields of learning is necessary. This century's learner has shifted the landscape of education in a more radically and compelling way than ever before. Of course, with radical change, there must be radical response. The very function, definition and ideology of the arts continue to morph, hybridize, and expand. Thus, the teaching of the arts must match this dynamic revolution and continue to adjust the trajectory of arts education.

While further growth, development, and the constant recognition of change will continue to be integral to innovative teaching and learning, the College of the Arts at Kennesaw State University is well positioned to become a leader in online arts education in the state of Georgia, if not the nation.

\section{REFERENCES}

[1] G. Kearsley and M. G. Moore, Distance Learning: A System View of Online Learning, Belmont, CA: Centage Learning, 2011.

[2] K. Marek, "Learning to teach online: Creating a culture of support for faculty," Journal of Education for Library and Information Science, vol. 50, no. 4, pp. 275-292, Fall 2009.

[3] T. Volery and D. Lord, "Critical success factors in online education," International Journal of Educational Management, vol. 14, no. 5, pp. 216-223, 2000. 
[4] M. A. Stankiewicz and E. Garber, "Cyber faculty: An experience in distance learning," Art Education, vol. 53, no. 1, pp. 33-38, January 2000.

[5] N. Kindelan, "Demystifying experiential learning in the performing arts," New Directions for Teaching and Learning, vol. 124, pp. 31-37, Winter 2010.

[6] M. M. Watts. "Introduction: Technology as catalyst," New Directions for Teaching and Learning, vol. 94, pp. 3-12, Summer 2003.

[7] I. E. Allen, and J. Seaman, Entering the Mainstream: The Quality and Extent of Online Education in the United States, 2003 and 2004, Newburyport, MA: Sloan Consortium, pp. 10-16, 2004.

[8] A. Carr-Chellman and P. Duchastel, "The ideal online course," British Journal of Educational Technology, vol. 31, no. 3, pp. 229-241, 2000.

[9] S. Y. Tucker, "Promoting socialization in distance education," Turkish Online Journal of Distance Education, vol. 13, no. 1, pp. 174-182, 2012.

[10] Y. E. De Vries, "The interactivity component of distance learning implemented in an art studio course," Journal of Art \& Design Education vol. 117, no. 2, pp. 180-184, December 1996.

[11] A. Sagun, D. Halime, and G. Mesut, "A framework for the design studio in web-based education," International Journal of Art \& Design Education vol. 20, no. 3, p. 332, 2001.

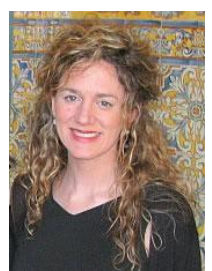

April Munson is an associate professor of art education in the College of the Arts at Kennesaw State University. She holds a PhD from the University of Illinois at Urbana Champaign, as well as an MA and BA from University of Kentucky. Her areas of interest include assessment, evaluation, distance learning, and qualitative research methodology. Her work has been published in journals such as Qualitative Research in Education and the International Journal for Education in the Arts. Her research has been part of conference proceedings including the National Art Education Association and the International Congress for Qualitative Inquiry.

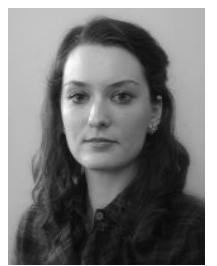

Lindsey Archer is an instructor of dance at Kennesaw State University, where she teaches online, hybrid, and face-to-face courses in dance history and theory. She held her masters of arts in dance theories and practices from the University of North Carolina at Greensboro. Archer spent time working with online dance education resource, Accelerated Motion: Towards a New Dance Literacy in America, and she has presented at numerous conference. Her research interests include, but are not limited to mediatized performance, dance and popular culture, and postcolonial studies in dance.

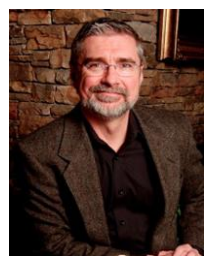

Edward Eanes is currently a professor of music history and a coordinator for arts in society: music at Kennesaw State University. After completing degrees in violin performance at Furman University and Florida State University, Eanes received a Ph.D. in musicology from Louisiana State University in 1995. In 1999, Scarecrow Press published his book Giuseppe Ferrata: Emigré Pianist and Composer. Other publications include articles in the New Grove Dictionary of Music and Musicians and reviews for MLA Notes. He has presented papers at the national conferences of the College Music Society, the Society for American Music, the Music Library Association, and the Hawaii International Conference on Arts and Humanities.

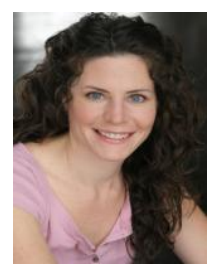

Dori Garziano held an MFA in theatre performance and a B.S. in elementary education from the University of Southern Mississippi. She has been an educator for the past 10 years, working with a variety of age groups from pre-school to college. She is certified to teach K-12 performing arts and specializes in vocal and movement work for the actor. In addition, Garziano spent three years studying and working in New York City. Currently, Garziano is an actor, stage manager, and teacher in the Atlanta area. She has worked at a variety of theatres including Georgia Ensemble Theatre, Georgia Shakespeare, Horizon Theatre, Theatre Emory, and the Alliance Theatre.

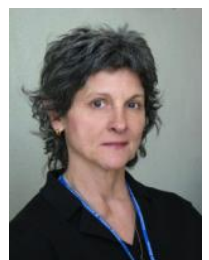

Deborah Hutchinson teaches small metals and jewelry design at Kennesaw State University. She introduced the classes following the completion of her masters in sculpture from Georgia State University in 2005. Deborah has worked for the Fulton County Arts Council's Art At Work Program. Her undergraduate degree from Georgia State University is in jewelry and metalsmithing. She has exhibited in local and national art shows, was a Niche Award Finalist in 1999. She received various awards for both her art jewelry and sculpture. She was a featured artist for HGTV on the Carol Duvall Show and her early work can be seen on the Silverhawk.com website in which she was the jewelry award recipient in 1999. Deborah also has a masters and bachelor degrees in education and has worked on the Pima Maricopa and Navajo reservations in Arizona. 